\title{
A simbologia de jardins, hortas e pátios na poesia de Antonio Machado
}

Volker Jaeckel Universidade Federal de Minas Gerais

El poeta en todo hallará motivo para mostrarse o sentirse melancólico, frente a un paisaje, frente a una mujer, frente

a la vida analizándose interiormente Juan Ramón Jiménez

\section{Jardins na cultura/literatura hispânica} incluía o chamado Al-Andalus, a geometria invadia o jardim, rodeado de uma vegetação sensual, voluptuosa e exuberante com repercussão sobre a literatura árabe clássica. A época áurea do jardim foi o século XVIII, quando se segue o modelo francês e o homem se sente vitalmente integrado à natureza, representando esta integração através de jardins, que são modelos em miniatura do mundo natural. O jardim e o horto se evidenciam na literatura como lugares da comunicação ideal, já que a natureza se opõe ao fragor da urbe. Por um lado, este espaço é o locus amoenus de encontros amorosos, por outro 
é um sítio com caráter solitário, onde o sujeito lírico contempla as belezas da natureza detidamente, onde o tempo não passa. Pensando nos aspectos sensuais do jardim, não se deve esquecer-se da identificação popular entre o jardim e a virgindade, e, por extensão do desfrute amoroso, o momento no qual também se anula o tempo. Esta identificação do jardim pode ser encontrada nas obras de Juan Ramón Jiménez, Premio Nobel de Literatura, poeta modernista e amigo de Antonio Machado que também faz referências a um lugar perdido, paraíso da infância. Em outros poetas espanhóis modernistas como, por exemplo, Pio Baroja, Miguel de Unamuno, Ramón del Valle-Inclán ou Manuel Machado encontramos descrições do jardim: elegância decadente nas formas, flores, sol, fonte, longitude do palácio, lentidão, imobilidade, estátuas, figuras difusas, solidão e morte, porém, os textos destes poetas não revelam tanta nostalgia e tanta intimidade na observação do jardim, nem tantas simbologias claras como as encontradas nos poemas de Antonio Machado.

Entre os poetas da geração de 27 e outros mais jovens, merecem a nossa atenção Jorge Guillén com a sua poesia Los jardines, Federico Garcia Lorca em Doña Rosita y El lenguaje de las flores, Luis Cernuda e, sobretudo, as hortas alicantinas do poeta Miguel Hernandez. Ojardim como lugar atemporal é encontrado também em Octavio Paz, ${ }^{1}$ e como jardim imóvel e anacrônico na poesia de Jorge Luis Borges (PÉREZ PAREJO, 2004).

\footnotetext{
${ }^{1}$ Octavio Paz teria negado a Antonio Machado a condição de poeta modernista, uma vez que este se comprazia na contemplação de campos, jardins bucólicos e hortas, sem levar em consideração os fenômenos da modernidade com a sua manifestação mais representativa, a cidade grande.
} 


\section{Antonio Machado e a geração de 98}

A Espanha no final do século XIX era marcada por um grande atraso econômico e social com respeito ao resto da Europa. O analfabetismo chegava a quase $80 \%$ da população e a tecnologia das poucas indústrias existentes estava completamente defasada. Com a derrota na guerra de 1898 e consequente perda das últimas colônias Cuba, Porto Rico e Filipinas para os Estados Unidos, as ilusões de grandeza nacional tinham que ser enterradas.

A geração de 98 é um grupo de escritores que nasceram entre 1864 e 1875 e cujos membros mais importantes são Miguel de Unamuno, Ramón del Valle-Inclán, Pio Baroja, Azorín e Antonio Machado. A união destes autores se deve ao desastre de 1898 e à decadência da Espanha. A imagem lamentável e a apatia que o país apresentava se transformaram numa preocupação comum dos intelectuais e pensadores. Os escritores analisam nas suas obras a origem dos males da Espanha, tentam propor soluções.

Um fator importante no âmbito da geração de 98 foi a contradição entre o desejo de alcançar o nível de desenvolvimento de outros países europeus e ao mesmo tempo as tentativas de conseguir uma reorientação para os valores profundos, eternos e próprios da Espanha, valores que diferenciam o país do resto das nações. O ensaísta, romancista e diplomata andaluz Angel Ganivet, grande admirador de Schopenhauer e Nietzsche, foi considerado um precursor desta geração pelas idéias articuladas no seu Idearium español (1897), no qual postulava determinantemente uma volta ao verdadeiro espírito da terra mãe espanhola: à coragem e ao cavalheirismo dos seus habitantes (ALVAREZ/ LOURENÇO, 1994, p. 233).

Os escritores de 98 pretendiam uma restauração do espírito espanhol que podia ser possível através da recuperação do "caráter verdadeiro" do país, destacando o autenticamente espanhol, defendendo também a regeneração da alma do país. O modelo desta Espanha profunda era a região de Castela. 
Dom Quixote era o símbolo do ideal e dos valores internos do povo espanhol, uma vez que ele também superestimava as suas forças e perdeu as suas lutas consequentemente. ${ }^{2}$

Para os autores deste movimento, Castela representava a Espanha castiça, enquanto no século XIX, para os viajantes românticos, a Andaluzia ocupava ainda este lugar, símbolo da Espanha típica e folclórica, tanto para os próprios espanhóis como também para os estrangeiros (JAECKEL, 1995, p. 87-89).

\section{A vida de Antonio Machado}

Antonio Machado nasce em 26 de julho de 1875 em Sevilha, segundo de cinco filhos de uma família modesta. O pai, Antonio Machado Alvarez, foi um importante folclorista, fundador da Sociedad de Folklore Andaluz e também um livrepensador anticlerical.

Cresce no Palácio de las Duenas, onde a família mora em apartamento alugado. ${ }^{3}$ Seu irmão Manuel Machado, onze meses mais velho, nasceu em outro suntuoso palácio da capital que não correspondia à incerta e precária situação econômica da família Machado. "También señala la huella perdurable que el patio sevillano, con su fuente y limonero correspondientes,

${ }^{2}$ Segundo GUMBRECHT (1991), o mito de Dom Juan é substituído pelo mito de Dom Quixote como consequência de uma ilusão da desilusão experimentada pelos pensadores e poetas do 98 , cujo discurso marcado pelo leitmotiv da regeneração e do conhecimento si próprio não só dominava a produção intelectual como também isolava a Espanha até 1936, quando já tinha passado completamente de moda, como comprovaram os acontecimentos históricos daquele ano.

${ }^{3} \mathrm{O}$ Palácio de las Dueñas, construído nos séculos XV e XVI é um dos principais patrimônios artísticos e arquitetônicos da cidade de Sevilha, residência temporária da Duquesa de Alba. 


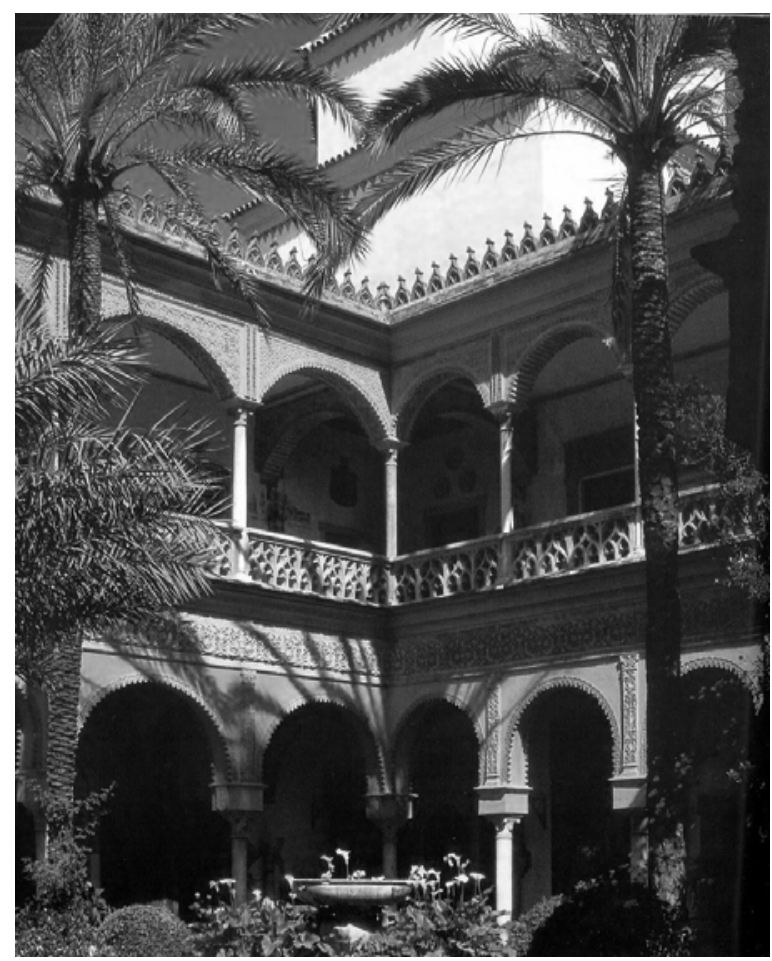

Palácio de las Dueñas, Sevilha. Fonte:http:/ /images.google.com.br/

dejó en él, al par que otros recuerdos infantiles..." (RIBBANS, 2003, p. 24).

Em 1883, seu avô é nomeado catedrático da Universidade Central de Madri e a família se muda para a capital. A formação do jovem Antonio é marcada pelos problemas econômicos da família e pela célebre Institución Libre de Enseñanza, fundada em 1876 como reação a um decreto que proibia o ensino de temas contrários ao dogma católico ou os ataques à monarquia. Era marcada pelo espírito laico, tolerante, democrático e pelo empenho científico (CATALÃO, 2005, p. 28).

Entre 1899 e 1902 viaja a Paris, trabalha como tradutor e conhece Rubén Darío. Em 1903 publica o seu primeiro livro de 
poemas Soledades. Em 1907 presta concurso para o cargo de professor de francês numa escola secundária em Soria, onde conhece Leonor Izquierdo, com quem se casa, tendo ele 34 anos e ela 16. Leonor adoece durante uma viagem a Paris, de tuberculose, e morre em 1912, motivo da depressão profunda de Antonio, que solicita transferência a Baeza (Jáen), onde vive com a mãe, dedicando-se aos estudos e ao ensino. Conhece Federico García Lorca, publica no mesmo ano o seu terceiro livro, intitulado Campos de Castilla, com o qual se aproxima mais dos autores da geração de 98.

Em 1917 muda-se para Segovia e em 1931 começa a trabalhar como professor em Madri. Desdobrou a sua personalidade reflexiva em Abel Martín e em outro professor apócrifo, Juan de Mairena (aluno de Abel Martin), cujas considerações foram publicadas a partir de 1934 na imprensa madrilenha. Este último comentava temas da atualidade através da dúvida poética, não metódica e do humor, seus recursos permanentes.

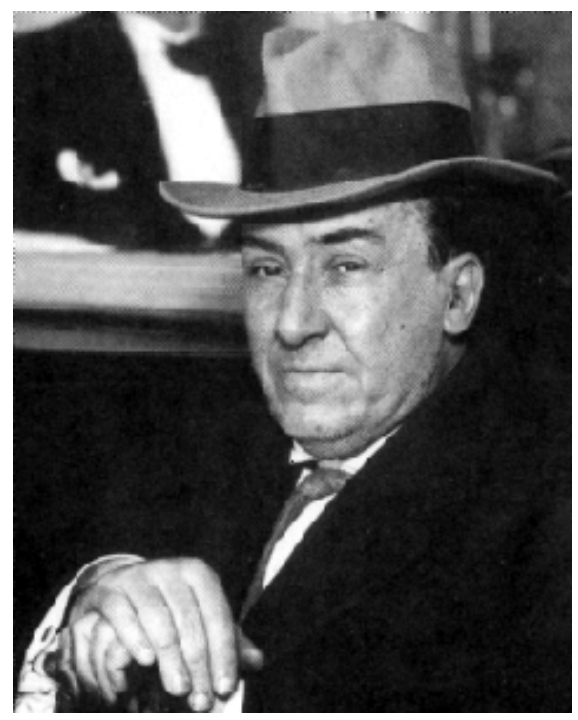

Antonio Machado 1936.

Fonte: http://images.google.com.br/ 
Em 1936, na véspera da Guerra Civil Espanhola, sai o livro Juan de Mairena: sentencias, donaires, apuntes y recuerdos de un profesor apócrifo, que é uma compilação de diversos textos com reflexões sobre questões metafísicas e poéticas. Em 1937 publica sua última obra, La guerra, e se muda para Valencia. No final da Guerra Civil Espanhola, em janeiro de 1939, atravessa com a mãe de 83 anos a fronteira com a França e morre em 22 de fevereiro de 1939, no exílio em Collioure. Sua mãe falece três dias depois.

O irmão Manuel, também poeta, que tinha vivido a Guerra Civil Espanhola na zona nacionalista e se tinha mostrado partidário do golpe de 1936, foi imediatamente ao cemitério, onde estava enterrado o seu irmão (STAUDER, 1998, p. 199)

\section{Simbologia e importância dos jardins em Antonio Machado}

Conhecendo a trajetória da vida de Antonio Machado, pode-se perceber que os jardins, as hortas e os pátios possuem significado especial na sua obra. Eles são muitas vezes relacionados à infância feliz do autor em Sevilha e fazem contraste com os campos áridos e inóspitos do planalto castelhano. O jardim é considerado um lugar acolhedor de paz e sossego, de luminosidade, de temperatura agradável, enquanto a terra castelhana inspira sentimentos de rejeição, de adversidade e de dureza.

Explica-se este contraste pelas experiências vividas por Machado que exercia sua profissão em Soria, a menor capital de província da Espanha, com 7000 habitantes na época. Não gostava nem de ensinar, nem da cultura francesa segundo as próprias palavras de Machado; teve um casamento breve e com fim trágico, fato que deixou o poeta abalado. Em sua memória ficam as lembranças do harmonioso jardim e de pátios andaluzes. 
A poesia de Antonio Machado tem uma constante: a tarde e seus desdobramentos semânticos. Dos 96 poemas de Soledades, Galerias, Otras Poesias, 36 fazem alguma referência a este período do dia. A tarde é o momento propício para a meditação, para o relaxamento, a reflexão sobre a própria vida, a saudade; é expressão da luta entre a luz e a sombra e também aparece como a premonição da morte.

A poesia de Machado possui muitas outras simbologias que aparecem repetidamente em seus versos e são importantes para o seu entendimento: a água significa o inexorável fluxo do tempo, o fluir da vida. A fonte é símbolo de desejos e ilusões, a água que brota e o caminho são a vida no seu transcurso, como lugar de peregrinação e de busca.

Nos textos da poesia intimista de Machado o jardim significa a intimidade e o espelho é o lugar onde se projetam as lembranças e os sonhos. A terra e o campo, muitas vezes, simbolizam a realidade solitária e o caráter agreste e inóspito da Espanha profunda.

A temática dos poemas gira em torno de questões complexas: o tempo e o fluir da vida humana, o problema da morte e da finitude. Estes são os temas centrais que inspiram a poesia machadiana. Com eles estão relacionados outros assuntos: a infância perdida, os sonhos e as paisagens constituem o marco para as meditações e o amor. $\mathrm{O}$ amor que se percebe nos poemas do poeta sevilhano pode ser considerado um amor desejado, mas não realizado ou correspondido, um amor místico, perdido e morto. Portanto, prevalece o sentimento da solidão que dá título ao livro, melancolia, tristeza, o vácuo da vida e a angústia vital, sentimentos universais que chegam a Antonio Machado como herança dos românticos, especialmente do conterrâneo sevilhano do século XIX, Gustavo Adolfo Béquer. 


\section{Jardín}

Lejos de tu jardín quema la tarde inciensos de oro en purpurinas llamas, tras el bosque de cobre y de ceniza.

En tu jardín hay dalias.

¡Malhaya tu jardín!... Hoy me parece la obra de un peluquero, con esa pobre palmerilla enana, y ese cuadro de mirtos recortados... y el naranjito en su tonel... El agua de la fuente de piedra no cesa de reír sobre la concha blanca

(MACHADO, 1997, p. 162)

O eu lírico passeia por uma paisagem com a qual se identifica, porém sente-se queimado por dentro, dolorido. Pára e recorda um jardim conhecido que passa por algumas mudanças. Antonio Machado plasma a lembrança pessoal da sua própria infância em várias ocasiões. Seja qual for o espaço, fica claro que toda a infância recordada é uma mistura de transcendência e inconsciência, de felicidade e angústia, que se reflete no simbolismo de Machado.

Os onze versos têm uma rima irregular, embora com tendência para onze sílabas. Podem-se distinguir duas partes do poema, a primeira formada pelos quatro primeiros versos e a segunda pelo resto do poema. Na primeira parte, o autor está encerrado no seu mundo de símbolos, a tarde é o ambiente predileto das evocações de Machado. O eu lírico parece ser melancólico e explica ao leitor o que se passa longe do jardim, onde os incensos circulam com sua típica cor de ouro, pelo bosque.

Na segunda parte, Machado fala do jardim, talvez abandonado, que é comparado de forma irônica com diversos elementos. O jardim abandonado é o recinto preferido das 
revelações de Machado, que buscava em cada objeto e em cada matiz evocar nos leitores uma lembrança paralela.

A observação irônica "la obra de un peluquero" compara o trabalho do jardineiro com o do cabeleireiro, uma vez que o jardim não se encontra em boas condições, e este fato provoca, no poeta, um sentimento de raiva.

Depois aparece a enumeração dos objetos que se encontram no pátio: a fonte como um curioso símbolo do novo, o fluxo da água recorda o passar inexorável do tempo. Também encontramos outra personificação, a da água que não sorri. $\mathrm{O}$ poema fala de como o passar do tempo afetou um jardim que na mente e na lembrança de Machado era muito diferente. Tratase de um poema simbolista e de temática intimista, que recorre a determinadas imagens para intensificar a expressão do sentimento. Ao mesmo tempo tenta articular as lembranças que comovem o sujeito lírico. É um poema de traços biográficos identificáveis, que expõe uma voz pessoal do eu lírico. Merece atenção o uso de pronomes e dos demonstrativos para o eu lírico marcar a sua presença, em diálogo com um interlocutor desconhecido, a quem pertence o jardim em questão. Das plantas são citadas as dálias, a palmeira anã, a onipresente laranjeira e os mirtáceos. Junto com o fluxo da água brotando da fonte de pedra, estas plantas podem simbolizar a harmonia dos diferentes elementos presentes num pátio andaluz, como Machado percebeu-o durante a sua infância sevilhana.

\section{Los jardines del poeta}

A Juan Ramón Jiménez

El poeta es jardinero. En sus jardines corre sutil la brisa con livianos acordes de violines llanto de ruiseñores, ecos da voz lejana y clara risa de jóvenes amantas habladores. 
Y otros jardines tiene. Allí la fuente le dice: Te conozco y te esperaba. Y él, al verse en la onda trasparente: ¡Apenas soy que ayer soñaba! $Y$ otros jardines tiene. Los jazmines añoran ya verbenas del estío, y son liras de aroma estos jardines, dulces liras que tañe el viento frío. $Y$ van pasando solitarias horas, y ya las fuentes, a la luna llena, suspiran en los mármoles, cantoras y en todo el aire sólo el agua suena.

(MACHADO, 1997, p. 231-232)

Este poema tem um caráter metaliterário, já que o poeta é comparado a um jardineiro, cuja tarefa é deter o tempo perene com a sua arte e criar mundos artificiais e fictícios com a sua música transformada em palavras. Existem constantes alusões às ondas, à fonte e à sonoridade da água. Pode-se constatar que Machado, nesta poesia, se refere ao livro Jardines lejanos (1904) do poeta Juan Ramón Jiménez que está dividido em três seções: Jardines galantes, Jardines místicos e Jardines dolientes, quando escreve "Y otros jardines tiene". Antonio Machado admirava muito esta obra, o que fica documentado numa carta ao poeta de Moguer:

Paréceme, en suma una obra madura y perfecta. Una tan fina sensibilidad como la de usted no existe, creo yo, entre poetas castellanos; tal dulzura de ritmo y delicadeza para las armonías apagadas, tampoco. Suavidad de sonidos, de tonos, de imágenes, de sentimientos. ${ }^{4}$

${ }^{4}$ MACHADO, 1997, p. 263. Apesar do entusiasmo pela obra, constata-se uma bifurcação entre o andaluz e o castelhano que acaba por separar os dois poetas, segundo Geoffrey. 
O próprio Machado consegue alcançar este tom suave através dos sons e imagens que evoca com a simbologia das flores, do ar, da lua e da água nesta poesia que expressa também a nostalgia das festas das estações mais cálidas do ano, quando se celebram as verbenas, festas muito populares, nas vésperas dos dias de santos como Santo Antônio, São Pedro, São João e da Virgem de Carmen com danças nas ruas, comidas típicas como churros e buñuelos. Deve-se observar a personificação das flores que sentem saudade destas festas tão típicas do folclore andaluz.

\section{VII}

El limonero lánguido suspende una pálida rama polvorienta sobre el encanto de la fuente limpia, y allá en el fondo sueñan los frutos de oro...

Es una tarde clara, casi de primavera, tibia tarde de marzo que el hálito de abril cercano lleva; y estoy solo, en el patio silencioso, buscando una ilusión cándida y vieja: alguna sombra sobre el blanco muro, algún recuerdo, en el pretil de piedra de la fuente dormido, $\mathrm{o}$, en el aire, algún vagar de túnica ligera.

En el ambiente de la tarde flota ese aroma de ausencia, que dice al alma luminosa: nunca, y al corazón: espera.

Ese aroma que evoca los fantasmas de las fragancias vírgenes y muertas.

Sí, te recuerdo, tarde alegre y clara, casi de primavera, tarde sin flores, cuando me traías 
el buen perfume de la hierbabuena, y de la buena albahaca, que tenía mi madre en sus macetas.

Que tú me viste hundir mis manos puras en el agua serena, para alcanzar los frutos encantados que hoy en el fondo de la fuente sueñan...

Sí, te conozco, tarde alegre y clara, casi de primavera.

(MACHADO, 1997, p. 93-94)

Este poema VII foi publicado pela primeira vez em 1903 na revista Helios com o título "El poeta visita el patio de la casa en que nació". Portanto, remete ao palácio De las Dueñas em Sevilha, onde Antonio Machado passou os primeiros anos da sua infância Deve ter sido escrito em 1898, por ocasião de sua visita a Sevilha antes de uma viagem a Paris, logo no início da sua carreira como poeta. Foi publicado em 1917 no livro Soledades, galerias y otros poemas.

O limoeiro parece ser uma projeção do eu poético, a relação entre os dois sublinha o sossego e a falta de ação visível. Este elemento típico dos pátios sevilhanos mantém uma relação metonímica com a fonte limpa, sobre a qual lança uma rama pálida e empoeirada (BORSATO, 2009, p. 770).

CARRO (1995) chega através da análise deste poema à conclusão de que Antonio Machado no fundo é um romântico, um sonhador que não quer realidades, senão ilusões e sonhos que se projetam sobre os objetos contemplados, sobre o fluxo do tempo e seu dinamismo. O ânimo do poeta é marcado por uma melancolia da chegada da tarde e do ocaso que significa o fim da vida.

A partir do verso 21 se manifesta de forma evidente o diálogo do poeta com a tarde, com a paisagem e com as lembranças. Trata-se da aproximação de momentos cronologi- 
camente opostos. Neste instante de reviver, o poeta está consumido pelo sonho, está ensimesmado e submerso na própria alma, um estado de ânimo que é comunicado ao leitor não diretamente, mas mediante os símbolos tarde e fonte. $\mathrm{O}$ poeta pretende harmonizar juventude e infância com a idade madura através do sonho que é o denominador comum dos diferentes momentos da sua vida (CARRO, 1995).

Machado consegue o efeito de recriação no leitor graças ao abundante uso de adjetivos que possuem uma função especificadora: lánguido, polvoriento, limpia, clara, casi de primavera, tíbia tarde de marzo.

Trata-se de um poema circular, uma vez que os mesmos elementos do início aparecem novamente no final. $\mathrm{O}$ aspecto formal encontra a sua correspondência no nível do conteúdo: presente e passado se fundem e se confundem, a tarde evocada pela alma infantil tem elementos fantasmagóricos que provocam uma emoção especial no poeta que contempla os espaços através da sua memória. A tarde e os seus sentidos aparecem em muitos poemas e possuem um simbolismo fúnebre. $\mathrm{O}$ espaço do pátio, em concordância com o marco temporal, tem o significado da infância, como também a fonte. Este pátio que aparece tantas vezes nos poemas de Machado com os vasos de flores da sua mãe evoca o aroma dos seus sonhos. ${ }^{5}$

Existe uma harmonia entre o subjetivo e o objetivo que se manifesta na busca pelos valores sensoriais, nesta busca tão típica dos modernistas, aparecem as sensações olfativas provocadas pelos cheiros no pátio andaluz, os quais ocupam um lugar destacado no poema (CARRO, 1995).

${ }^{5}$ Parece que o pátio machadiano cumpre a mesma função que as frutíferas hortas de Orihuela na obra de Miguel Hernández (19101942), poeta morto muito jovem num presídio franquista em Alicante, cujo centenário de nascimento acaba de ser comemorado. 
A temática deste como de outros poemas de Soledades se situa em torno de complexas questões: o tempo e o fluxo da vida humana, a morte e o problema do que existe no além, Deus. Existem outros temas vinculados a estes assuntos centrais: a infância perdida, os sonhos e as paisagens. O tema do amor fornece à sua poesia um matiz especial e os sentimentos (solidão, tristeza, melancolia, vazio de viver, angústia vital) não só dominam os poemas, como também dão o título ao livro e podem ser considerados uma herança romântica com certos vestígios na tradição poética de outro conhecido sevilhano: o poeta romântico Gustavo Adolfo Béquer (1836-1870).

\section{Retrato $^{6}$}

Mi infancia son recuerdos de un patio de Sevilla, $\mathrm{Y}$ un huerto claro donde madura el limonero;

Mi juventud, veinte años en tierra de Castilla;

Mi historia, algunos casos que recordar no quiero.

Ni un seductor Mañara, ni un Bradomín he sido -ya conocéis mi torpe aliño indumentario-, Más recibí la flecha que me asignó Cupido, Y amé cuanto ellas pueden tener de hospitalario.

${ }^{6} \mathrm{O}$ já conhecido poema Retrato ganhou ainda mais fama na muito popular interpretação do cantor e compositor catalão Joan Manuel Serrat que gravou esta canção em 1976, em Milão. No dia 26 de Julho de 2000 , por motivo do $125^{\circ}$ aniversário do poeta sevilhano, o cantor e compositor Joan Manuel Serrat recebeu em Sevilha o I Premio Internacional Antonio Machado por sua contribuição para a divulgação da obra machadiana, sob a forma do álbum "Dedicado a Antonio Machado" (DIAZ ARENAS, 2010 e http://www. youtube.com/watch?v=VGHmqIuu3o4\&feature=fvw) 
Hay en mis venas gotas de sangre jacobina, Pero mi verso brota de manantial sereno; $Y$, más que un hombre al uso que sabe su doctrina, Soy, en el buen sentido de la palabra, bueno.

Adoro la hermosura, y en la moderna estética Corté las viejas rosas del huerto de Ronsard; Más no amo los afeites de la actual cosmética, $\mathrm{Ni}$ soy un ave de esas del nuevo gay-trinar.

Desdeño las romanzas de los tenores huecos Y el coro de los grillos que cantan a la luna. A distinguir me paro las voces de los ecos, Y escucho solamente, entre las voces, una.

¿Soy clásico o romántico? No sé. Dejar quisiera Mi verso, como deja el capitán su espada: Famosa por la mano viril que la blandiera, No por el docto oficio del forjador preciada.

Converso con el hombre que siempre va conmigo - quien habla solo espera hablar a Dios un día -; Mi soliloquio es plática con este buen amigo Que me enseño el secreto de la filantropía.

Y al cado, nada os debo; debéisme cuanto he escrito.

A mi trabajo acudo, con mi dinero pago

El que me cubre y la mansión que habito, El pan que me alimenta y el lecho en donde yago Y cuando llegue el día del último viaje Y esté al partir la nave que nunca ha de tornar, Me encontraréis a bordo ligero de equipaje, Casi desnudo, como los hijos de la mar.

(MACHADO, 2003, p. 101-102) 
Este poema abre a coleção Campos de Castilla, ${ }^{7}$ foi escrito numa data próxima à instalação do poeta em Soria, e publicado pela primeira vez no jornal El liberal, no dia 1 de fevereiro de 1908. É o melhor documento poético que nos revela o estado de ânimo de Machado no momento de iniciar a sua carreira como professor de escola secundária. Neste poema fica patente o afastamento dos valores frívolos da vida boêmia da capital, dentre os quais menciona-se o chamado "donjuanismo" e as etiquetas literárias (RIBBANS, 2003, p. 17).

"Retrato" é considerado uma autobiografia do poeta, já que explica-se porque abandona a vida ociosa de boêmio em Madri para trabalhar e ganhar a vida na província, como professor de francês na Escola Secundaria de Soria. O poema é dominado pelo sentimento de independência espiritual e material.

Menciona-se a sua infância em Sevilha. Os vinte anos em terras de Castela se referem a Madri e suas cercanias. Não existe nenhuma alusão direta ou remota a sua nova residência em Soria, nem a sua paixão por Leonor, a qual tinha conhecido em outubro de 1907.

Voltando para a primeira das três partes que compõem o poema, encontramos um pátio de laranjeiras e um horto de limoeiros. Pátio, laranjeira, fonte, limoeiro e horto formam parte do léxico simbólico de Antonio Machado e significam sempre infância, tranquilidade, espírito feliz e sossego, com leve timbre de melancolia causado pela lembrança (URRUTIA, 1975 , p. 923). Laranjeira e limoeiro servem para simbolizar a sua infância ao longo de toda a obra, enquanto olmo e carvalho

${ }^{7}$ Como ressalta DÍAZ ARENAS (2010), este poema mantém uma relação de intertextualidade com duas poesias do seu irmão Manuel, "Adelfos", de Alma (1902) e "Retrato" do livro El mal poema, publicado somente em 1909. Ambas as poesias se encontram, tal como "Retrato", de Antonio Machado, também no início de cada coleção. 
representam as terras altas e secas de Castela e, portanto, a idade madura.

O poema divide-se em três partes: nos primeiros três versos descreve-se ao leitor os acontecimentos importantes da sua vida, as recordações de sua infância, onde se encontram o pátio de Sevilha e o jardim, onde cresce o limoeiro. No quarto verso, parece que o poeta não quer revelar todas as circunstâncias da vida e deseja esquecer alguns episódios da vida anterior, evoca sua vida desordenada e folgada de bebedor, sem chegar ao alcoolismo, como ele mesmo diz.

Nos versos cinco e seis, Machado liga o dom-juanismo a certa forma de vestir-se, Juan de Mañara é a personificação do Don Juan que inspirou o herói da peça teatral, intitulada Juan de Mañara, escrita por Antonio e Manuel Machado. ${ }^{8}$ A outra personagem relacionada à lenda de Don Juan Tenório é o famoso Marquês de Bradomín. ${ }^{9}$

Neste poema reconhece a sua acentuada herança revolucionária que abrange várias gerações de ancestrais que foram contra o clero e tinham fama de serem maçons, porém, confessa ter somente algumas gotas de sangue jacobino. Caracteriza-se desta forma a sua rebeldia e o inconformismo com a situação da Espanha naquela época. Machado acredita nas suas ações e as suas convicções políticas não enturvam o discernimento claro e racional. Ele mesmo confessa que a sua vida está mais marcada por resignação que por rebeldia e é exatamente esta resignação que marca o teor geral da obra do poeta (URRUTIA, 1975, p. 928-9).

${ }^{8}$ Miguel de Mañara era um filantropo sevilhano (1627-1679) que também inspirou o nome do escritor apócrifo Juan de Mairena.

${ }^{9}$ Trata-se de uma figura mítica da literatura espanhola, um refinado e decadente Don Juan, recriado por Valle-Inclán nas Memórias Del Marqués de Bradomín, onde aparece como católico e sentimental. 
Por um lado, alguns dos poemas de Campos de Castilla confirmam o seu vínculo ao grupo dos autores de 98 , por outro, constituem uma abertura para fora, para o novo, marcada por uma decadência melancólica, já que as paisagens machadianas de Castela são habitadas por pessoas de carne e osso, por camponeses e operários pobres (NEUSCHÄFER, 1994, p. 335-336).

\section{Conclusão}

Para Antonio Machado o jardim possui uma simbólica muito forte, uma vez que está relacionado aos pátios de sua infância em Sevilha. Estes jardins harmoniosos e luminosos contrastam com os campos de Castela que, ásperos e inóspitos, incorporam o profundo da alma espanhola, atraente e fascinante, repelente e desprezível. Machado mantém com a paisagem castelhana uma relação ambivalente, parecida à que tem com a Espanha como estado nação. A lembrança do jardim e por conseguinte, da infância é marcada por certa felicidade e ao mesmo tempo por uma melancolia permanente. Desde o início da sua obra poética o inexorável fluxo da vida que não pode ser detido preocupa o poeta, uma das vozes mais importantes da geração de 98. Antonio Machado, em consequência de algumas mudanças importantes em sua vida, consegue ampliar o espectro da sua escrita e integra nos versos a sua percepção da problemática da alma de Espanha/ Castela de forma mais acentuada.

Devido ao olhar nostálgico de Machado para os pátios sevilhanos percebe-se que ele se encontrava deslocado em Soria como se vivesse em uma paisagem de deserto. Mais tarde, porém, revela certa admiração pela região inóspita do centro da Península Ibérica, sua gente simples do campo, e tem dificuldades para adaptar-se novamente à vida na Andaluzia.

Por outro lado, percebe-se em alguns poemas de Campos de Castilla o olhar crítico e preocupado com a Espanha e com as 
desigualdades que já nas primeiras décadas do século XX estavam evidentes. O próprio poeta parece pressagiar, segundo as interpretações mais comuns, toda a fatalidade desta divisão do país, que ele mesmo imortalizou. Porém, para Machado, as duas Espanhas significavam o passado que estava morrendo e o presente apático, as duas não eram opções desejáveis, já que não sentia inclinação por nenhuma das duas, mas temia sempre que uma delas afogasse todas as possibilidades de renovação da outra.

Españolito que vienes al mundo te guarde Dios.

Una de las dos Españas

ha de helarte el corazón

(MACHADO, 2003, p. 230)

\section{Referências}

ALVAREZ, Eloísa; LOURENÇO, Antonio Apolinário. História da literatura espanhola. Porto: Edições ASA, 1994.

BORSATO, Fabiane R. Antonio Machado e João Cabral de Melo Neto constroem Sevilhas. V CONGRESSO DOS HISPANISTAS BRASILEIROS. Anais... Belo Horizonte: Universidade Federal de Minas Gerais, 2 a 5 de setembro de 2008. Disponível em http:/ / www.letras.ufmg.br/espanhol/Anais/anais_paginas_\%205031004/Antonio\%20Machado.pdf

CARRO, Carlos Arconada. Calas románticas en el poema VII de Soledades de Machado. V ENCUENTRO DE JÓVENES HISPANISTAS. Actas... Las Palmas de Gran Canaria, 1995. Disponível em: http:/ /www.ucm.es/info/especulo/bibl_esp/jhispani/arcona10.html

CATALÃO, Marco Aurélio Pinotti. Estudo Introdutório. Antonio Machado. Obra poética. Estudo introdutório, antologia e trad. por Marco Auréio Pinotti Catalão. Brasília: Embajada de España / Consejeria de Educación, 2005, p. 13-60. 
DÍAZ ARENAS, Ángel. "Retrato" de Antonio Machado. Vida, obra y destino 135 años después: 26 de julio de 2010. Disponível em http:/ / pekin.cervantes.es /imagenes /image/biblioteca / antonio\%20machado\%20vida.pdf.

GUMBRECHT, Hans- Ulrich: Eine Geschichte der spanischen Literatur. 2 vols. Frankfurt: Suhrkamp, 1991.

JAECKEL, Volker. Das Andalusienbild in der Landeskunde. Grenzgänge 4 (1995), p. 82-93.

MACHADO, Antonio. Campos de Castilla, 14. ed. de Geoffrey Ribbans. Madrid: Ediciones Cátedra, 2003.

MACHADO, Antonio. Soledades. Galerias. Otros poemas, 14. ed. de Geoffrey Ribbans. Madrid: Ediciones Cátedra, 1997.

NEUSCHÄFER. Hans-Jörg. Spanische Liteaturgeschichte. Stuttgart, Weimar: Metzler Verlag, 1994.

PÉREZ PAREJO, Ramón. Poética del jardín: Del locus amoenus al jardín novísimo. Revista Almiar, (Margen Cero) 2004. Disponivel em: http:/ / www.margencero.com/articulos/p_parejo.htm

RIBBANS, Geoffrey. Introducción. In: MACHADO, Antonio. Campos de Castilla, 14. ed., Madrid: Ediciones Cátedra, 2003, p. 11-88.

RIBBANS, Geoffrey. Introducción. Antonio Machado. Soledades. Galería. Otros poemas. 14. ed., Madrid: Ediciones Cátedra, 1997, p. 13-61.

STAUDER, Thomas. La repercusión del 18 de julio de 1936 en la vida y la obra de Manuel Machado. Mechthild Albert (Ed.). Vencer no es convencer. Literatura e ideologia del fascismo español. Frankfurt: Vervuert, Madrid: Iberoamericana, 1998, p. 199-220.

URRUTIA, Jorge. Bases comprensivas para un análisis del poema "Retrato", Cuadernos Hispanoamericanos, 304-7, octubre de 1975enero de 1975, II, p. 920-43. 


\section{Resumo}

O poeta modernista Antonio Machado, uma das vozes mais marcantes da geração de 98, mantinha uma relação muito estreita, na sua obra, com o tema do jardim, o qual constituía uma lembrança essencial da sua infância sossegada na cidade de Sevilha. Neste artigo, quatro poemas são contextualizados e analisados. Neles encontra-se uma forte simbologia dos elementos jardim, pátio e horta, os quais constratam com os campos inóspitos de Castela.

\section{Resumen}

El poeta modernista Antonio Machado, considerado una de las voces más distinguidas de la poesía española del siglo veinte, abarca en muchos poemas el tema del jardín que representa los recuerdos esenciales de una infancia tranquila en Sevilla. En este artículo será apresentado el contexto biográfico e histórico antes de entrar en el análisis de cuatro poesías, con fuerte simbología de los elementos jardín, patio y huerta que contrastan con los campos inhóspitos de Castilla. 